\title{
An Australian Feeling for Snow \\ Towards Understanding Cultural and Emotional Dimensions of Climate Change
}

ANDREW GORMAN-MURRAY

—CARING about Climate Change: do Australians haVe 'A FEeling For SNOW'?

What does snow mean to Australians? I asked this question of participants in a study on the cultural significance of snow conditions in Australia that was undertaken throughout 2008 and 2009. This investigation was prompted by models of the impact of climate change on snow conditions in mainland Australia published in 2003 by the Commonwealth Scientific and Industrial Research Organisation (CSIRO). The CSIRO projected a significant reduction in the area, duration and depth of winter snow cover in the Australian Alps as a result of rising temperatures and precipitation changes associated with global warming: the area receiving at least thirty days of snow cover will decrease by 14 to 54 per cent by 2020 and 30 to 93 per cent by 2050, while the area with at least sixty days snow cover will decrease by 18 to 60 per cent by 2020 and 38 to 96 per cent by $2050 .{ }^{1}$ Simultaneously, maximum snow depths will decline and the snowline will rise: at Mt Kosciuszko, 'the snowline elevation on 1 September is predicted to rise from the present average of 1461 metres to between 1488 and 1624 metres by 2020'.2 These figures suggest the effect of climate change on snow conditions in Australia will be significant at the lower end of the spectrum and devastating at the higher end. 
I reacted 'emotionally' to these projections: I was shocked and disappointed, especially about the imminence of climate change impacts. As several media commentaries have noted, these models intimate that extant snow conditions-and the mainland alpine and subalpine 'snow country' comprising the Australian Alpsmay all but vanish from the continent by the middle of this century. ${ }^{3}$ The emotional tenor of my response to projected snow loss was the catalyst for a research project: What do snow conditions mean to Australians? This question was framed in the context of climate change and its impending impacts on Australian snow conditions. At one level, I wanted to know if Australians cared about the diminution of snow and, consequently, those landscapes and ecosystems dependent on snow cover. ${ }^{4}$ Moreover, I wanted to think about how concerned reactions might be channelled into ameliorative actions against climate change. Snow matters to the viability of the mainland ski tourism industry, of course-and this is the site of most work on cultural implications of snow loss 5 - but I was interested in broader meanings and feelings associated with snow cover and wondered, might there be wider lessons to be learnt from our responses to imminent changes in Australian snow conditions?

This article reflects on some of the findings of this project. I begin with a conceptual framework, arguing for the need to appreciate localised interpretations of climate change through cultural meanings. Here, I also outline data collection methods: a survey, participant observation and focus group discussions. I then discuss several emergent themes. The survey indicated that distinct geographical patterns were associated with Australian snow conditions. Snow conditions and cultures were linked with rural, regional and 'natural' mountain wilderness areas rather than urban settings. This positions the project under the remit of rural cultural studies, addressing climate-culture connections discursively linked to, and materially grounded in, regional spaces. Simultaneously, respondents suggested that the uneven distribution of Australia's snow conditions-concentrated in the continent's south-east-means snow loss matters in localised areas. While many respondents referred to the Australian Alps, Tasmania was also proffered as a prime example. I consequently conducted participant observation and a focus group in Hobart, the capital of Tasmania, about the local meaning of snow conditions. This article analyses the contextual material gathered, which provides telling details about meanings and feelings associated with snow conditions because, unlike the 
Australian Alps, Tasmania's snow country is not associated with the economic viability of ski tourism. Instead, this case elicits broader reflections on the everyday cultural significance of snow conditions, and the emotional tenor of changes to local snow cover. Discussants demonstrated snow loss mattered culturally and emotionally, compromising local cultural activities and meanings, and invoking emotive responses.

Before moving on, I must clarify the local specificity of this analysis and the importance of such an approach. There is notable localised variability of climate, culture and, thus, climate-culture connections across Tasmania. After initially discussing the regionalisation of imaginative and material geographies of Australian snow conditions, the penultimate section of this article focuses exclusively on Hobart residents' perceptions and experiences of immediate (Hobartian) and wider (Tasmanian) snow cover changes. Through theoretically informed empirical discussions of these regional and local geographies I aim to advance understandings of the spatial contingency of climate-culture relationships in Australia. To do this, I argue that conceptual refinement must be informed by, and emerge through, measured discussion of grounded empirical examples. Socially relevant conceptualisations come to light through close consideration of contextual data. This is particularly pertinent with something as needy of pragmatic results as arresting global warming. Abstract(ed) conceptualisations of cultural dimensions of climate change are not the most appropriate avenue for assisting grounded action and prompting changes in cultural practices and behaviours. In conclusion, then, I argue that climate change impacts on local cultural and emotional attachments can contribute to practical and political arguments about addressing climate change.

\section{—CULTURAL AND EMOTIONAL DIMENSIONS OF CLIMATE CHANGE: CONCEPTS AND METHODS}

My project responds to Hulme's recent call for more cultural geographical work on climate change. ${ }^{6}$ Hulme, whose interdisciplinary approach to climate change straddles both human and physical geography, asserts that since the mid-1980s climate change policy and public discourse has been shaped by the natural sciences, where climate is 'defined purely in physical terms, constructed from meteorological observations, predicted inside the software of Earth system science models and governed (or not) through multi-lateral agreements and institutions'.7 This 
approach is incomplete, he contends, because it is disembodied from the everyday human activities, observations and feelings that give meaning and value to climate, and by extension, climate change. ${ }^{8}$ Instead, Hulme argues that 'registers of climate can be read in memory, behaviour, text and identity as much as they can be measured through meteorology', and thus the full impact of climate change can only be properly understood when its physical dimensions are also interpreted by their entwined cultural meanings. ${ }^{9}$ Consequently, he urges a re-examination of climate change which 'needs to start with contributions from the interpretative humanities and social sciences, married to a critical reading of the natural sciences, and informed by a spatially contingent view of knowledge'.10

The present study contributes to the re-examination of climate change in terms of cultural meanings. In particular, I deploy a cultural geographical approach, taking up Hulme's last point above regarding the re-examination of climate change: cultural understandings of climate are spatially and locally contingent. ${ }^{11}$ The dominant natural science approach to climate has enumerated-rather than 'felt'local changes in temperature and precipitation, pegging these statistics into planetary-scale models of global warming. This universal modelling technique has cleaved changes in weather patterns from their localised cultural meanings and constitutive values. Rather than a visceral, embodied and emotional experience of drought, rain or snow, meteorological models of global warming de-contextualise local knowledge of climate patterns and weather experiences. ${ }^{12}$ This spatial dissociation engenders severe problems for policy-driven attempts to advocate for effective responses to climate change, especially in the developed West. ${ }^{13}$ Over the last decade a range of surveys has shown that the globalised discourse of climate change has distanced and de-contextualised the problem from our everyday lifeworlds ${ }^{14}$ - particularly in the West, with our reliance on air-conditioning and heating to 'terra-form' our immediate environment.15 This provides a way for individuals to express concern, but avoid behavioural change: It's a global problem, so what I do locally won't really make a difference. ${ }^{16}$

Thankfully, as recent reports by Hulme and Head ${ }^{17}$ acknowledge, new work has begun to explore local culture-climate connections to show the importance of interpreting weather patterns and climate change through local meanings and values. For instance, Strauss and Orlove's collection Weather, Climate, Culture 
presents local case studies from around the world to demonstrate that 'our different cultures shape the way we think about and respond to the weather', and thus 'as we face the impacts that climate change processes bring to our communities, we must recognize that our perceptions as well as our reactions are shaped by our cultures'.18 Local meanings of climate have also been critical in a continental-scale nation like Australia. Sherratt, Griffiths and Robin's collection A Change in the Weather: Climate and Culture in Australia provides various historical and geographical case studies which interrogate the relationship between climate and Australian culture. ${ }^{19}$ Together they argue that local weather patterns and climate trends in Australia have been 'invested with meanings that cannot be read from a thermometer or rain gauge' and have 'merged with the imagining of nationhood, with the construction of an Australian identity'.20 This project follows the path initiated by these scholars, focusing on local and national values around a particular climate patternAustralian snow conditions-in order to advance localised cultural and emotional prompts regarding climate change meanings and responses.

In particular, understanding individuals' emotional responses to altered landscapes and seasonal rhythms has been absent from research on climate change to date. ${ }^{21}$ This lacuna demands attention. As I suggested above, individuals 'feel' their environments through 'embodied' engagements with seasonal weather conditions, ${ }^{22}$ and it is clear that climate change will fundamentally alter seasonal patterns of precipitation, humidity and temperature. ${ }^{23}$ Yet much work on 'human dimensions' of climate change (as it is called by natural scientists) utilises risk perception lenses that gauge public opinion on the relative importance of climate change vis-à-vis other socioeconomic and environmental issues. ${ }^{24}$ These approaches favour cognitive rational-choice models, which assume individuals 'distance' themselves from their environments to make 'rational' assessments of climate risk over considerations of sensory engagements with place. ${ }^{25}$ They therefore exhibit the same problems as scientific models of global warming, cleaving human perceptions from everyday experiences of landscape, climate and weather. Insights from the burgeoning field of emotional geographies might address this gap. ${ }^{26}$ Within this body of work, emotions are understood not as interior mental states, but relational achievements that provide the connective tissue between individuals and place. ${ }^{27}$ While there are several traditions informing emotional geographies, 
phenomenological approaches are most relevant to my concerns here. ${ }^{28}$ Under the banner of humanistic geography, phenomenological geographers have emphasised the importance of experiential dimensions of place, felt through embodied practices, for understanding local and regional cultural values.29 In this light, emotional responses are situated embodied engagements that cement place attachments and meanings, and thus provide new insight into local meanings of climate change.

For this study a mixed method data collection approach was adopted, and a range of qualitative data has been gathered. The intent of using mixed methods was to access multi-scaled and multi-local perspectives on the cultural significance of Australian snow conditions in light of climate change. This included meanings framed at both the scales of the nation and the region, with localised case studies (below). Initially, a qualitative online survey was conducted between March and October 2008. Thirty questions were designed to elicit general knowledge of the geography of Australian snow conditions, personal experiences of snow, and reactions to the projected loss of snow cover due to climate change. Through this collection process I wanted to gain a national-scale perspective, so an online survey was used to expediently access views from across the country. An invitation was distributed through various online groups focused on environment and climate awareness, including Weather Zone, Envirotalk and Climate Change Action. ${ }^{30}$ Importantly, these groups largely comprise interested members of the general public, not environmental scientists, and thus this purposeful sampling was intended to contact people interested (and/or sceptical) about climate change scenarios. Ninety-five responses were received: forty-three from New South Wales, thirty from Victoria, seven from Tasmania, five each from Queensland and Western Australia, three from South Australia, and two from the Australian Capital Territory. Of the respondents, 95.8 per cent had British or European ancestry and their ages ranged from sixteen to sixty-eight years. I have analysed these data elsewhere, alongside archival materials, to interrogate national cultural values of the Australian Alps vis-à-vis climate change. ${ }^{31}$ I use them here to understand the spatial and local contingency underpinning meanings of snow.

The second stage of data collection was designed to access localised practices, feelings and values associated with snow conditions, and comprised focus groups and participant observation in places strongly linked with snow culture. 
Accordingly, I spent a week in Hobart in July 2008, in winter, observing everyday interactions between local residents and snow conditions. As intimated in the introduction, I chose Tasmania rather than the Australian Alps because of the comparatively lesser prominence of commercial ski tourism, and more 'mundane' relationships with snow cover. I interacted with locals, asked about the historical geography of snow in Hobart and Tasmania, and observed casual utterances and conversations about local snow conditions. I also conducted a focus group with local residents about what snow means to Hobartians and Tasmanians, including links with local cultural practices and values and how these are being affected by changing climatic trends. Participants were recruited with the help of a key informant with 'insider' knowledge of local snow cultures. These discussions and observations provided valuable insights into cultural and emotional attachments to local snow conditions. In the penultimate section of this article I interpret this data, combined with the seven survey responses from Hobartians, to understand meanings and feelings associated with climate change impacts on local climateculture connections. First, I discuss what the survey revealed about the cultural geography of Australian snow, including the place of Hobart and Tasmania in this spatial imaginary.

—SPATIAL CONTINGENCIES: IMAGINATIVE AND MATERIAL GEOGRAPHIES OF AUSTRALIAN SNOW

In the survey I specifically asked respondents: What is your knowledge of snow conditions in Australia? Write in as much detail as you like about the places where it snows. The seventy-six respondents who answered this question indicated that particular geographical patterns were associated with Australian snow conditions. This, in turn, reveals some of the cultural meanings about snow in Australia, and how they differ from other countries. The results, listed in frequency of mentions, are contained in Table 1.

What taken-for-granted geographical connections are evident through the responses? Table 1 indicates that Australian snow conditions are overwhelmingly associated with rural areas. Out of twenty-three discrete localities named, fourteen are rural regions-including those making up the top thirteen responses. Overall, rural regions across the country were mentioned 266 times, while urban centres (with populations more than 20,000 people) were mentioned only twenty-seven 


\begin{tabular}{c|l|c}
\hline Rank & Region or locality & $\begin{array}{c}\text { Number of } \\
\text { mentions }\end{array}$ \\
\hline 1 & Snowy Mountains (NSW) & 54 \\
2 & Victorian High Country/Victorian Alps & 50 \\
3 & Tasmania/Tasmanian Highlands & 38 \\
4 & Northern Tablelands and Barrington Tops (NSW) & 16 \\
5 & Blue Mountains (NSW) & 15 \\
6 & Central Highlands (Victoria) & 14 \\
7 & Great Dividing Range in southern Queensland & 14 \\
8 & Central West Slopes of Dividing Range (NSW) & 13 \\
9 & Stirling Ranges and south-west Western Australia & 13 \\
10 & Tasmanian lowlands & 11 \\
11 & Flinders Ranges, Mt. Lofty Ranges, Adelaide Hills (SA) & 10 \\
12 & Victorian lowlands and coastal ranges (e.g. Otways) & 9 \\
13 & Southern NSW and the Monaro & 8 \\
14 & Hobart (Tasmania) & 7 \\
15 & Canberra (ACT) & 4 \\
16 & Orange (NSW) & 4 \\
17 & Armidale (NSW) & 3 \\
18 & Melbourne - suburbs (Victoria) & 3 \\
19 & Bathurst (NSW) & 2 \\
20 & Ballarat (Victoria) & 1 \\
21 & Goulbourn (NSW) & 1 \\
22 & Bendigo (Victoria) & 1 \\
23 & Uluru (NT) & 13 \\
& & \\
\hline
\end{tabular}

Table 1: Regions and cities associated with snow conditions in Australia, from seventy-six respondents

times (these are italicised in the table). In other words, respondents were almost ten times more likely to mention a rural region than a city. This discursive association between snow conditions and rural space is also shown in the language used to describe snow-bound areas in Australia: the Australian Alps, for instance, is the 
snow country'.32 This contrasts with the cultural-geographical associations of snow conditions overseas, especially in Eurasia and North America, where snow is as much an urban phenomenon as a rural one. Discursive imaginaries and everyday knowledge render various large cities snow-bound in the northern hemisphere winter-for example, Moscow and St Petersburg (Russia), Toronto and Montreal (Canada), Chicago and Minneapolis (US), Harbin (China), Sapporo (Japan) and Oslo (Norway). In the 'north' there is no necessary equivalent to our 'snow country'snow falls across both urban and rural areas-while in Australia most snow falls in sparsely populated rural areas. As one respondent (Anglo-Australian male, 54, Melbourne) noted, 'Very few Australians live above the snowline, or in fact anywhere near it. Australian snow coverage is all remote.' Indeed, the only major cities that receive (a few centimetres of) snow every few years are Hobart and Canberra, as the survey results intimated. 33

This configuration of the Australian snow country within an urban-rural binary can be further refined. As recent geographical work in rural cultural studies stresses, the meaning of 'the rural' in Australia is highly differentiated, spanning pastoral, bush, outback and other imaginaries in a multi-scalar fashion. ${ }^{34}$ Applying this diversity to the present case, Table 1 shows that cultural understandings of Australian geography predominantly link snow conditions with mountainous terrain across the continent-the Great Dividing Range, Flinders Ranges and Stirling Ranges, for instance-and in particular, with alpine and subalpine mountain areas, notably the Snowy Mountains, the Victorian High Country and the Tasmanian Highlands. These are particular 'ideal-types' of rurality: to adapt Bell's terms, 'wildscapes', associated with wilderness and pristine nature, and 'adventurescapes', groomed for outdoor sporting activities. ${ }^{35}$ Bell's third 'species' of rural space, the agrarian-pastoral 'farmscape', is almost absent from associations with Australian snow conditions; the only noted region that really fits is the Central West Slopes of the Dividing Range in New South Wales. Ecologically speaking, the connections between alpine and subalpine mountain terrain and snow conditions is not surprising. Snow is, after all, one of the defining weather patterns of alpine environments. But what this does indicate is that Australians' understandings of the geographical range of snow conditions is much more contained than that of residents of overseas countries, where non-alpine snow cover across lower-lying 
farmland areas is common during winter, especially the prairie and steppe farmscapes of Eurasia and North America.

Furthermore, snow conditions are predominantly linked with the south-east of the continent. This is not surprising-for this is where the higher mountains are concentrated-but what is important is that within this geographical pattern, Tasmania is prominent in the spatial framing of the Australian snow country. This geographical imaginary is multifaceted. First, Tasmania ranked third in terms of regional associations with snow conditions-thirty-eight respondents (50 per cent) iterated this link. Significantly, only six of these were Tasmanian residents. This indicates that the association between Tasmania and snow conditions is common in wider national imaginaries of regional variation and geographical localisation of climatic conditions. Second, Tasmania is one of the few regions where snow is not purely linked with alpine highlands: thirteen of these respondents invoked Tasmania-as a state, in its entirety-with snow conditions (no other state or territory was linked thus, not even the Australian Capital Territory); a further eleven people specifically mentioned snowfall on the Tasmanian lowlands. Third, of those few cities noted as snowy places, Hobart ranked highest with seven mentions, almost twice as many as the next two cities, Orange and Canberra.

The implication of these various associations is that Tasmania, as a state, is discursively linked with a snowy climate in national cultural and spatial imaginaries more than other Australian states. Snow conditions, and associated local knowledge and practices, appear to be part of what defines a distinct Tasmanian identity and imaginary. As one Tasmanian respondent (Anglo-Australian male, 68, Hobart) noted, 'Snow makes Tasmania different from the mainland', while another (AngloAustralian male, 32, South Hobart) asserted, 'I love snow. I think it's nice having four seasons in a year.' Paralleling this theme, several respondents suggested that the impact of climate change on snow cover would matter more in those places with a regular connection to snow conditions, particularly Tasmania (as well as the Australian Alps). Following Hulme's argument, then, there is a need to pay attention to the local meanings and feelings associated with particular climatic conditions to better understand how climate change will impact on cultural values and practices and, consequently, make stronger arguments for behavioural changes that might assist in ameliorating the effects of global warming. Given that a strong link between 
snow conditions and Tasmanian lifestyles emerged in the survey responses, I undertook fieldwork in Hobart about the meaning of climate change impacts on Hobartian and wider Tasmanian snow conditions. I analyse those findings in the penultimate section of this article.

—CULtURAL AND EMOtional dimensions of SNOW loss In HOBART AND TASMANIA

Analyses of the cultural and emotional dimensions of snow loss in Tasmania is drawn here from three data sources outlined earlier: a one-and-a-half hour focus group discussion held in Hobart on this topic, combined with replies from seven survey respondents resident in Hobart, and participant observation in Hobart during winter 2008. The focus group discussants comprised two women (both 30something) and two men (one 30-something, one 50-something), all tertiaryeducated, environmentally conscious Anglo-Australians. ${ }^{36}$ It is important to note that the data is based on responses from a particular part of Tasmania-Hobartand that in analysing this material I am therefore focusing on perceptions and experiences of snow loss provided by Hobartians. In describing their personal encounters with snow, both focus group and survey respondents drew attention to local experiences of (changes in) snow cover; that is, on conditions and engagements in and around Hobart. But, simultaneously, the respondents also reflected on their experiences of snow, and perceptions of snow cover changes, across Tasmania more widely. As respondents themselves suggested, such multi-scaled engagement is perhaps enabled by the smaller size of Tasmania compared to other states. The data thus elicited responses to both Hobartian and wider Tasmanian changes in snow cover, and analysis of these discussions, responses and observations educed several themes about spatially contingent cultural values and emotional facets of Tasmania's diminishing snow conditions. I focus on four intersecting themes: local sensitivity to snow cover change; local cultural meanings about snow conditions and climate change; the role of accessibility to snow in cultural practices and values; and emotional responses to climate change impacts on snow conditions and cultures. While I discuss each in turn-roughly—they are not discrete elements, of course. Rather, they interleave to produce a multifaceted net of climate-culture connections, and these intersections are apparent below. 
While the CSIRO advocates more meteorological work be done on climate change impacts on Tasmanian snow conditions, ${ }^{37}$ respondents indicated that local snow loss is well underway. Take, for instance, these survey responses:

I believe that Hobart's snowfall numbers and intensity have greatly fallen off in recent decades. [Anglo-Australian male, 68, Glenorchy]

People say it used to be colder and Hobart has received snow-I have yet to see it other than on Mt Wellington [adjacent Hobart] and other peaks in Tasmania. [British male, 64, Lindisfarne]

Really, over the last twenty-five years Mt Wellington's snowfalls have got a lot less!! [Anglo-Australian male, 32, South Hobart]

Likewise, focus group discussants noted a considerable decline in snowfall and snow cover over the last two decades. Susan has lived all her life in Ferntree, a higherelevation Hobart suburb which has felt the effects of changing snow conditions:

Susan: I grew up in Ferntree at about 500 metres altitude on Mt Wellington and we used to get snowed in two or three times a year in the '70s and '80s, and it hasn't happened for-it now only happens once every two or three years.

Andrew: Have you spoken to other people in the area about that as well? Have they seen the same thing?

Susan: Oh yeah, it's well understood, well observed, definitely. A visible sign of how the climate's changing.

John, meanwhile, reiterated the diminishing snow conditions higher up Mt Wellington:

Certainly there's been a lot less snow up there than there used to be. We've had years when there's been almost no snow right through winter ... It's a combination of warmer winters and drier winters that has meant there has been less snow up there than there has been. Well, I think Susan is right - the last time there was regular snowfall was the late '80s and perhaps just into the early '90s. Since then it's been, as I'm saying, less precipitation and warmer in the winter.

These assertions affirm Hulme's argument about the need to recognise meanings of climate change as locally contingent. Weather is felt locally, through everyday embodied practices, which in turn contextualise-or 'ground'-the 
cultural values associated with (changing) climatic conditions. I want to juxtapose two instances of climate-culture connectivity-an observation I noted, subsequently reworked by the focus group - to highlight the importance of local meanings when thinking about the challenges posed by climate change. In Hobart I visited Wrest Point Casino, and walked through a corridor of 'representative' images of Tasmania. Over half the photographs featured snow-covered landscapes or wintery alpine mountaintops. It seemed through these images that snow conditions were integral to Tasmanian imaginaries. I related this during the focus group to ask discussants if they thought snow conditions were an important aspect of Tasmanian identity which differed from mainland Australia, and if climate change would detrimentally affect this 'snowy' Tasmanian identity. While they agreed that such images commonly symbolised Tasmania, they saw these as a 'marketing construct', not a reflection of how snow conditions shape the everyday meanings and cultural practices of Tasmanians themselves. Rather than climate change and diminishing snow compromising symbolic images of Tasmania, discussants were more concerned with the impact on local cultural values and practices. For instance, John said:

I think for me it's very much a problem for us as locals that that snow experience is becoming less frequent and to some extent non-existent. I just love taking people into the snow if I can. I love taking my kids into the snow because I knew they'd like it. I have a lot of visitors to Tasmania and if I got an opportunity I would take them into the snow, particularly if they come from countries where they don't get snow experiences-or even if they come from Adelaide.

In describing accessible snow experiences, John hinted at a key way snow conditions entwine with local cultural practices and values. While Tasmania's southerly latitude compared to mainland Australia means snow is more likely, simultaneously the small size of the island-state-again, compared with mainland states-means that Tasmanians have tangible interactions, rather than simply imaginative associations, with snow conditions. Indeed, discussants reflected on the role of scale and accessibility in Tasmania's snow culture:

Susan: Geographically, it's a small area. It would be interesting to know by state what level of population lived within half a day's drive of snow when 
it does happen. Here [in Hobart] we've got half-50 per cent of the population-at the base of Mt Wellington. That's pretty significant, I think. Being a Tasmanian, it [snow] is part of the rich tapestry of life. I think of it as being distinctive from mainland Australia.

Linda: Even though I've only been in Tasmania twelve years, snow is part of my photo album, my history of where I recreate [take recreation] and live and play. It's a backdrop. It's beautiful.

All the participants agreed that the geographical size of Tasmania meant that more people were proximate to and regularly experienced snow conditions as part of their everyday lives than most other Australians. Dan, for instance, provided his own observation on snow's routine place in local lives:

I was at the supermarket this morning and I overheard three conversations about the weather and they all ended with, "The snow will be down low today.' That was their conversations. 'I bet the snow is down at Ferntree', or 'People will be fighting hard to get to work this morning.'

In this vignette, Dan, like Susan, referred to the common presence of snow on Mt Wellington, Hobart's mountain backdrop, which rises 1271 metres above sea level. ${ }^{38}$ During winter, as Susan noted, snow easily falls in higher elevation suburbs at the foot of the mountain, such as Ferntree. Indeed, while I was there the snow reached down to five hundred metres above sea level (Figure 1). But moreover, both survey and focus group participants indicated that snow can be a year-round event on the mountain; as one survey respondent (Anglo-Australian male, 32, South Hobart) wrote:

On Mt Wellington the snow can fall anytime of the year. I have seen snow settle as low as $600 \mathrm{~m}$ in summertime, and just this February [2008] we had about a $10-12 \mathrm{~cm}$ fall on the mountain.

The constant possibility and presence of snow on Mt. Wellington embeds snow conditions in local Hobartian cultures and values. Moreover, this locally contingent climate-culture relationship has a crucial emotional register as well. John evocatively expressed this emotional connection to local weather patterns, and particularly diminishing snow conditions, catalysed through Mt Wellington:

When you live in Hobart, people talk about the moods of the mountain, and snow is one of the important moods of the mountain. And we're not 
getting that particular mood as often as we feel we perhaps ought to be getting it and that is a disappointing thing ... If you're not getting snow as part of that experience for very long periods of time you do notice that something has changed. It probably hits a lot of people in the face that that is no longer a mood which we're experiencing and we can't take it for granted any longer.

Through evoking the 'moods of the mountain', John not only reinforced the climate change impact on locally contingent cultural meanings of snow conditions, but demonstrated that these local climate-culture connections have a powerful emotional resonance which is being upset by the effects of global warming. Indeed, emotive language permeated discussants' speech, articulating underlying senses of angst, disappointment and disorientation associated with diminishing local snowfall.

The sense of emotional connection and dissonance with ebbing snow cover extends beyond the vicinity of Hobart, into the wider Tasmanian countryside as well. Accessibility to rural, mountainous and wilderness areas means, as Susan said, 'we've got such an outdoor culture down here. There are so many people that go bushwalking and cross-country skiing.' The discussants focused on cross-country skiing as a Tasmanian cultural practice-and emotive experience-seriously affected by snow loss. In winter, much of the countryside was accessible for cross-

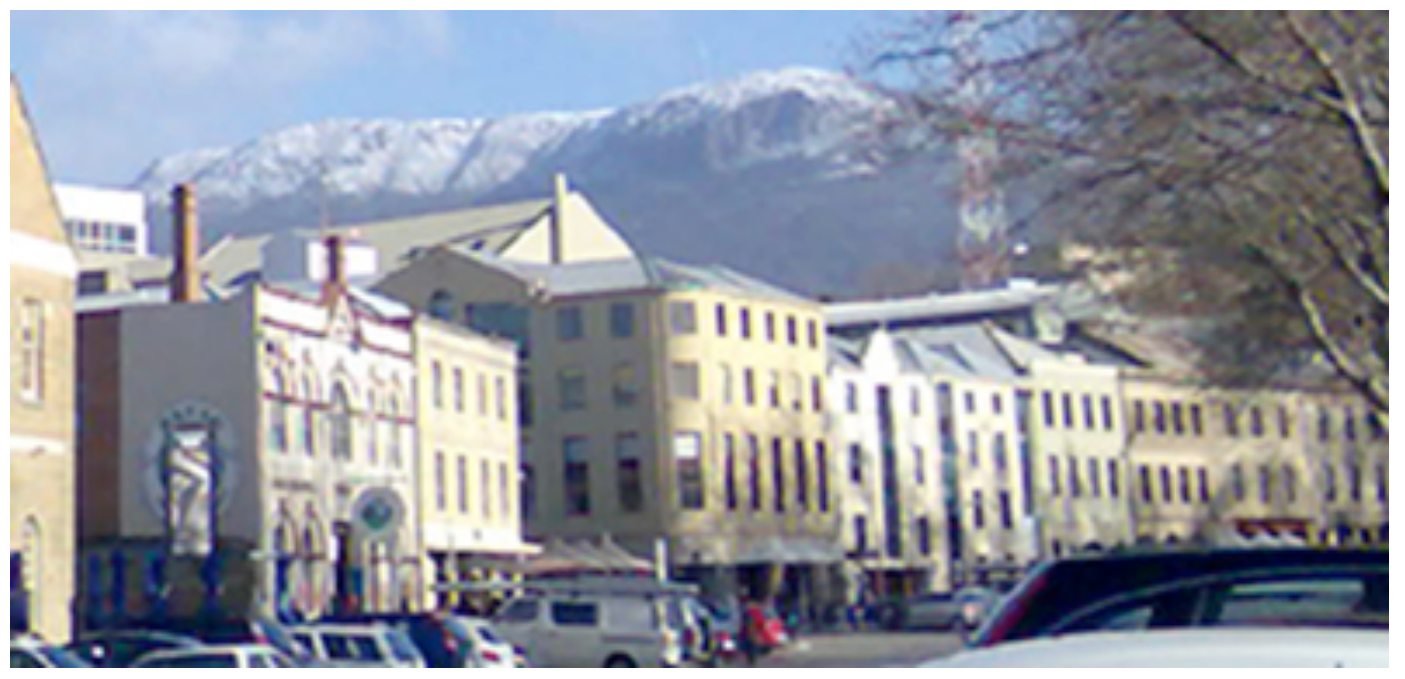

Figure 1: Snow-capped Mt Wellington from Salamanca Place, 4 July 2008 (photograph: Andrew Gorman-Murray) 
country skiing; participants mentioned the Snowy Range, the Wellington Range, the Central Highlands, Mt Field and Ben Lomond. Susan intimated that cross-country skiing was popular because it facilitated an emotional appreciation of the natural environment in snow cover:

Skiing is an extension of bushwalking for me, and I think I'm not alone in Tasmania. If you bushwalk you're quite likely to also want to go out in the snow in winter. Bushwalkers tend to put on cross-country skis and go out for an experience that involves appreciating the aesthetics in the back country, physical challenge and the solitude and beauty of that environment.

However, cross-country skiing has been progressively limited over the last decade because of noticeable decline in the regularity, depth and duration of snow across the traditional cross-country zones. All the discussants had been forced to curtail their skiing excursions over this time, and expressed disappointment over the loss of wilderness snow conditions. This emotional response had at least three levels of meanings. John and Susan lamented the damaging impact of diminished snow cover on local environments and endemic ecosystems; Dan and John conveyed frustration that their children wouldn't have the same opportunity to experience regular snow conditions; all regretted that the peaceful silence and serene beauty of snowcovered bush landscapes was a less frequent experience.

- HOPING FOR CHANGE: PRACTICAL AND POLITICAL OUTCOMES

Climate change is threatening parts of the world's cultural and historical heritage, but the possible loss or damage to these irreplaceable sites is rarely represented in economic estimates of the cost of climate change ... changes in local climate may ... relegate to history some climate-related features that once reinforced shared values and memories. ${ }^{39}$

As Dow and Downing contend, in altering natural environments, seasons and weather patterns, global warming seriously affects cultural values and heritage as well. Modification of cultural practices and meanings in turn evokes emotive responses as lifestyles, expectations and experiences are reoriented in line with changing climatic conditions. Cultural adaption to a changing climate comes at an 
emotional cost. However, the cultural and emotional fallout from climate change is only now gaining attention from researchers, governments and policy-makers.

By considering the meaning of Australian snow conditions in light of global warming, and particularly through a case study of the cultural and emotional dimensions of Hobart's and Tasmania's diminishing snow conditions, I have sought to advance these often overlooked elements of climate change. This was a relatively small-scale sample and the specific findings are not readily generalisable. But that's precisely the point of the study-to access and understand localised meanings of climate change. As Hulme argued, to fully grasp the impact of climate change, and craft effective policy and behavioural responses, we must recognise that climate is interpreted through localised cultural values and emotive experiences. While climate change science, statistics and protocols are reified at a planetary scale, the impact of climate change is felt locally through adjusting embodied practices. By reconnecting climate change research with local meanings and feelings, we can better understand what may prompt behavioural changes which might ameliorate some of the effects of global warming on landscapes, weather and lifestyles. ${ }^{40}$ Reflecting local values and feelings back to constituencies might help individuals and communities realise they can contribute to climate change action through their everyday practices. As John said at the end of the focus group discussion, 'There's every reason to try and arrest the rapidity with which change takes place.'

Consequently, I argue that in terms of practice and politics, cultural geography research has much to offer policy-makers charged with addressing climate change, complementing the monitoring and measurements contributed by natural sciences. As suggested above, these advances centre on the cultural and emotional tangibility of the local scale as a prompt for action. The saliency of proposals projected at the national scale may be hard for people to perceive because this scale is beyond individuals' lifeworlds. But focusing initiatives at the local level may better encourage changes in everyday practices-such as reducing carbon emissions from households and businesses through modified consumption habitsbecause people have an attachment to their local environment and its seasonal shifts. This is the immediate context of their homes, lives and livelihoods. As Lorenzoni and Pidgeon argue, 'situating climate change "in the locality" will provide the driver to initiate behavioural change, as the benefits become tangible to active 
participants' within their own lifeworlds. ${ }^{41}$ In turn, successful 'local level initiatives may set the precedent' for and prompt wider-ranging national policies. ${ }^{42}$ Indeed, emotional and sensory experience of our local environment is a fundamental part of our quality of life, and thus should crucially inform the terms of social justice and environmental policy at all scales. 43

How, then, might this project also address and advance the burgeoning work in rural cultural studies? Rural cultural studies is an unruly field, comprising a range of issues and approaches. ${ }^{44}$ The point of commonality is a sense of material and imaginative geography, with questions of rurality and regionality at the fore. Extending the above assertions, what this particular project underlines is the highly differentiated nature of rurality in Australia, in terms of localities, scales, landscapes, communities and climatic conditions. As Gorman-Murray, Darian-Smith and Gibson have pointed out, rural images in and of Australia range across associations with the bush, the outback, pastoralism, mining, indigenous title, idyllic communities, commodified nature tourism, inter alia. Ebbing snow cover adds another landscape and layer to Australian rural imaginaries: the sensitivity of alpine wilderness and regional snow country to changing climatic conditions. Drought and temperature increases associated with global warming not only affect farming communities, but also a range of other cultural practices and communities embedded in rural and regional Australia. The case of Tasmania's diminishing snow-like that of mainland Australia-foretells the severe, but differentiated, impacts climate change will have on many rural and regional communities. Awareness of these different ruralities, regionalities, communities and impacts is needed to effectively address the challenge of climate change.

Andrew Gorman-Murray is a research fellow in Human Geography at the University of Wollongong. His rural cultural research interests include heritage, tourism, festivals, place-making, sexual minorities in regional Australia, and cultural dimensions of environmental and climate change. This work has been published in Environment and Planning A, Antipode, Gender, Place and Culture, Australian Geographer, Australian Humanities Review, Rural Society, Journal of Tourism and Cultural Change and M/C Journal. <andrewgm@uow.edu.au> 


\section{-ACKNOWLEDGEMENTS}

Thanks to Emily Potter and Clifton Evers for their encouragement, and the referees for their constructive criticisms on the initial submission. The project was supported by funding from the University of Wollongong's GeoQuEST Research Centre.

\footnotetext{
-NOTES

${ }^{1}$ Kevin Hennessy, Penny Whetton, Ian Smith, Janice Bathols, Michael Hutchinson and Jason Sharples, The Impact of Climate Change on Snow Conditions in Mainland Australia, CSIRO Atmospheric Research, Aspendale, Victoria, 2003.

${ }^{2}$ Hennessy et al, p. 5; Neville Nicholls, 'Climate Variability, Climate Change and the Australian Snow Season', Australian Meteorological Magazine, vol. 54, no. 3, 2005, pp. 177-85. Variation in projected snow cover and snowline change results from low and high impact scenarios around temperature and precipitation changes. The low impact scenario is $+0.2^{\circ} \mathrm{C}$ and +0.9 per cent precipitation (over 1990 levels) by 2020 , and $+0.6^{\circ} \mathrm{C}$ and +2.3 per cent precipitation by 2050 . The high impact scenario is $+1^{\circ} \mathrm{C}$ and -8.3 per cent precipitation by 2020 , and $+2.9^{\circ} \mathrm{C}$ and -24 per cent precipitation by 2050 .

${ }^{3}$ Stephanie Peatling, '2100, A Climatic Odyssey', Sydney Morning Herald, 5-6 July 2008, pp. 1, 6; Sarina Talip, 'Alps to be Marketed to Overseas Visitors as Unique', Canberra Times, 17 June 2008, p. 4.

${ }^{4}$ Significant snow cover loss spells the end of alpine and subalpine ecosystems in Australia, including adapted fauna like mountain pygmy possums and alpine tree frogs. See various chapters in Ken Green (ed.), Snow: A Natural History; An Uncertain Future, Australian Alps Liaison Committee, Canberra, 1998; Catherine Pickering, Roger Good and Ken Green, Potential Effects of Global Warming on the Biota of the Australian Alps, Report for the Australia Greenhouse Office, 2004.

${ }^{5}$ Urs König, Tourism in a Warmer World: Implications of Climate Change due to Enhanced Greenhouse Effect for the Ski Industry in the Australian Alps, Universitat Zurich, Zurich 1998; Urs König, 'Climate Change and the Australian Ski Industry', in Ken Green (ed.), Snow, pp. 207-23; Sharon Bicknell and Phil McManus, 'The Canary in the Coalmine: Australian Ski Resorts and their Response to Climate Change', Geographical Research, vol. 44, no. 4, 2006, pp. 386-400; Hennessy et al.

${ }^{6}$ Mike Hulme, 'Geographical Work at the Boundaries of Climate Change', Transactions of the Institute of British Geographers, vol. 33, no. 1, 2008, pp. 5-11.

${ }^{7}$ Hulme, p. 6.

${ }^{8}$ John Thornes and Glen McGregor, 'Cultural Climatology', in Stephen Trudgill and André Roy (eds), Contemporary Meanings in Physical Geography: From What to Why? Arnold, London, 2003, pp. 173-97; Julie Doyle, 'Picturing the Clima(c)tic: Greenpeace and the Representational Politics of Climate Change Communication (1994-present)', Science as Culture, vol. 16, no. 2, 2007, pp. 129-50.

${ }^{9}$ Hulme, p. 7.

${ }^{10}$ Hulme, p. 5.

${ }^{11}$ See also Irene Lorenzoni and Nick Pidgeon, 'Public Views on Climate Change: European and USA Perspectives', Climatic Change, vol. 77, nos 1-2, 2006, pp. 73-95.

${ }^{12}$ For further details on the cultural significance of seasonal weather patterns, see a special issue of Landscape Research on 'Landscape and Seasonality', vol. 30, no. 2, 2005, edited by Hannes Palang, Gary Fry, Jussi S. Jauhiainen, Michael Jones and Helen Sooväli.

${ }^{13}$ Joseph DiMento and Pamela Doughman (eds), Climate Change: What it Means for Us, Our Children, and Our Grandchildren, MIT Press, Cambridge, 2007; Doyle 2007; Kersty Hobson, 'Reasons to be Cheerful:
} 
Thinking Sustainably in a (Climate) Changing World', Geography Compass, vol. 2, no. 1, 2008, pp. 199214.

${ }^{14}$ Rachel Slocum, 'Polar Bears and Energy-efficient Lightbulbs: Strategies to Bring Climate Change Home', Environment and Planning D: Society and Space, vol. 22, no. 3, 2004, pp. 413-38; Irene Lorenzoni, Sophie Nicholson-Cole and Lorraine Whitmarsh, 'Barriers Perceived to Engaging with Climate Change among the UK Public and their Policy Implications', Global Environmental Change, vol. 17, nos 3-4, 2007, pp. 445-59; Lorenzoni and Pidgeon, p. 87; Hulme, p. 8.

${ }^{15}$ Russell Hitchings, 'Geographies of Embodied Outdoor Experience and the Arrival of the Patio Heater', Area, vol. 39, no. 3, 2007, pp. 340-8; Russell Hitchings and Shu-Jun Lee, 'Air Conditioning and the Material Culture of Routine Human Encasement', Journal of Material Culture, vol. 13, no. 3, 2008, pp. 251-65.

${ }^{16}$ See Hobson.

${ }^{17}$ Lesley Head, 'Cultural Ecology: Adaptation-Retrofitting a Concept?', Progress in Human Geography, published on 6 July 2009 as doi: 10.1177/0309132509338978.

${ }^{18}$ Sarah Strauss and Benjamin Orlove, 'Up in the Air: The Anthropology of Weather and Climate', in Sarah Strauss and Benjamin Orlove (eds), Weather, Climate, Culture, Oxford, Berg, 2003, p. 6. See also Benjamin Orlove, Ellen Wiegandt and Brian H. Luckman (eds), Darkening Peaks: Glacier Retreat, Science and Society, University of California Press, Berkeley, 2008.

${ }^{19}$ Tim Sherratt, Tom Griffiths and Libby Robin (eds), A Change in the Weather: Climate and Culture in Australia, National Museum of Australia Press, Canberra, 2005.

${ }^{20}$ Tim Sherratt, 'Human Elements', in Sherratt et al., p. 9; Neville Nichols, 'Climate and Culture Connections in Australia', Australian Meteorological Magazine, vol. 54, no. 4, 2005, pp. 309-19; Deb Anderson, 'Drought, Endurance and "the Way Things Were": The Lived Experience of Climate and Climate Change in the Mallee', Australian Humanities Review, issue 45, 2008, pp. 67-81.

${ }^{21}$ See also Anthony Leiserowitz, 'Climate Change Risk Perception and Policy Preferences: The Role of Affect, Imagery, and Values', Climatic Change, vol. 77, no. 1, pp. 45-72.

${ }^{22}$ Hannes Palang, Gary Fry, Jussi S. Jauhiainen, Michael Jones and Helen Sooväli, 'Landscape and Seasonality-Seasonal Landscapes', Landscape Research, vol. 30, no. 2, 2005, pp. 165-72; Kenneth Olwig, 'Liminality, Seasonality and Landscape', Landscape Research, vol. 30, no. 2, 2005, pp. 259271;Tim Ingold, 'Rethinking the Animate, Re-animating Thought', Ethnos, vol. 71, no. 1, 2006, pp. 9-20.

${ }^{23}$ In eastern Australia this will be experienced through changes in the El Niño-Southern Oscillation, a crucial predictor of rainfall variability and drought.

${ }^{24}$ I am grateful to one of my reviewers for offering this insight.

${ }^{25}$ For example, Gary Yohe, 'Toward an Integrated Framework Derived from a Risk-management Approach to Climate Change', Climatic Change, vol. 95, nos 3-4, 2009, pp. 325-39; Lorenzoni and Pidgeon. See also Leiserowitz, pp. 46-7.

${ }^{26}$ This includes the following edited collections: a special issue of Social and Cultural Geography, 'Embodying Emotion, Sensing Space', vol. 5, no. 4, 2004, edited by Joyce Davidson and Christine Milligan; Joyce Davidson, Liz Bondi and Mick Smith (eds), Emotional Geographies, Ashgate, Aldershot, 2005; Mick Smith, Joyce Davidson, Laura Cameron and Liz Bondi (eds), Emotion, Place and Culture, Ashgate, Aldershot, 2009.

${ }^{27}$ Joyce Davidson and Christine Mulligan, 'Embodying Emotion Sensing Space: Introducing Emotional Geographies', Social and Cultural Geography, vol. 5, no. 4, 2004, p. 524; see also Liz Bondi, Joyce Davidson and Mick Smith, 'Introduction: Geography's “Emotional Turn”', in Joyce Davidson, Liz Bondi and Mick Smith (eds), Emotional Geographies, Ashgate, Aldershot, 2005, pp. 1-16; Mick Smith, Joyce Davison, Laura Cameron and Liz Bondi, 'Geography and Emotion-Emerging Constellations', in Mick Smith, Joyce Davidson, Laura Cameron and Liz Bondi (eds), Emotion, Place and Culture, Ashgate, Aldershot, 2009, pp. 1-18. 
${ }^{28}$ Other approaches include feminist, psychoanalytic and non-representational geographies (Smith, Davidson, Cameron and Bondi, pp. 10-13). Non-representational theory focuses on 'affect', which is also favoured in wider cultural scholarship. It is important to note, however, that 'affect' and its attendant theories comprise only one of several strands of emotional geographies, and in this paper I focus on 'emotions' rather than 'affect'. Indeed, within geography and anthropology there is an emerging division between the perspectives of 'emotion' and 'affect'. In these debates, emotions are understood as socially relational and accessed through reflection, while affects are ineffable, fleeting and not necessarily captured through language. Since much of my data-such as survey and focus group material-provides spoken and written reflections on personal engagements with snow, I am arguably dealing with emotions rather than affect. For more on these ongoing debates, see Deborah Thien, 'After or Beyond Feeling? A Consideration of Affect and Emotion in Geography', Area, vol. 37, no. 4, 2005, pp. 450-4; Divya Tolia-Kelly, 'Affect-An Ethnocentric Encounter? Exploring the 'Universalist' Imperative of Emotional/Affectual geographies', Area, vol. 38, no. 2, pp. 213-17; Andrew Beatty, 'Emotions in the Field: What are we Talking About?', Journal of the Royal Anthropological Institute, vol. 11, no. 1, pp. 17-37; Richard C. Powell, 'Learning from Spaces of Play: Recording Emotional Practices in High Arctic Environmental Sciences', in Mick Smith, Joyce Davidson, Laura Cameron and Liz Bondi (eds), Emotion, Place and Culture, Ashgate, Aldershot, 2009, pp. 115-32; Smith, Davidson, Cameron and Bondi, pp. 12-13.

${ }^{29}$ Smith, Davidson, Cameron and Bondi, pp. 10-11.

${ }^{30}<$ www.weatherzone.com.au, www.envirotalk.com.au>, $<$ au.groups.yahoo.com/group/ClimateChangeAction>.

${ }^{31}$ Andrew Gorman-Murray, 'Before and After Climate Change: The Snow Country in Australian Imaginaries', M/C Journal, vol. 11, no. 5, <http://journal.mediaculture.org.au/index.php/mcjournal/article/viewArticle/65>. The archival material includes D. G. Moye, Historic Kiandra: A Guide to the History of the District, Cooma-Monaro Historical Society, Cooma, 1959; Klaus Hueneke, Kiandra to Kosciusko, Tabletop Press, Canberra, 1987; Laura Neal, It Doesn't Snow Like it Used to: Memories of Monaro and the Snowy Mountains, Stateprint, Ultimo, 1988; John Merritt, Currango Summers: A Snow Belt Pastoral Property 1851-1946, Turalla Press, Bungendore, 2003; Norman Clarke, Kiandra-Gold Fields to Ski Fields, Cremorne1.com Self Publishing, Sydney, 2006; Hugh Capel, Kiandra Historical Society, <www.kiandrahistory.net>.

${ }^{32}$ Australian Alps Liaison Committee, Explore the Australian Alps: Touring Guide to the Australian Alps National Parks, New Holland Publishers, Sydney, p. 16.

${ }^{33}$ Even these cities are paralleled with rural 'wildscapes' (Bell 2006)-Hobart, capital of the 'natural state', Canberra, Australia's 'bush capital'.

${ }^{34}$ Andrew Gorman-Murray, Kate Darian-Smith and Chris Gibson, 'Scaling the Rural: Reflections on Rural Cultural Studies', Australian Humanities Review, issue 45, pp. 37-52.

${ }^{35}$ David Bell, 'Variations on the Rural Idyll', in Paul Cloke, Terry Marsden and Patrick Mooney (eds), Handbook of Rural Studies, Sage, London, 2006, pp. 149-160.

${ }^{36}$ Pseudonyms are used throughout.

${ }^{37}$ Hennessy, p. 39.

${ }^{38}$ Fiona Polack, 'Place and Space: Views from a Tasmanian Mountain', in Ruth Barcan and Ian Buchanan (eds), Imagining Australian Space: Cultural Studies and Spatial Inquiry, UWA Press, Nedlands, 1999, pp. 145-57.

${ }^{39}$ Kirstin Dow and Thomas Downing, The Atlas of Climate Change, University of California Press, Berkeley, 2007, p. 66.

${ }^{40}$ Hobson, pp. 204, 208-9.

${ }^{41}$ Lorenzoni and Pidgeon, p. 89.

${ }^{42}$ Ibid. 
43 Emily Brady, 'Aesthetic in Practice: Valuing the Natural World', Environmental Values, vol. 15, no. 3, 2006, pp. 277-91; Jennifer Foster, 'Environmental Aesthetics, Ecological Action and Social Justice', in Mick Smith, Joyce Davidson, Laura Cameron and Liz Bondi (eds), Emotion, Place and Culture, Ashgate, Aldershot, 2009, pp. 97-114.

${ }^{44}$ David Carter, Kate Darian-Smith and Andrew Gorman-Murray, 'Rural Cultural Studies: Introduction', Australian Humanities Review, i45, 2008, pp. 27-36. 